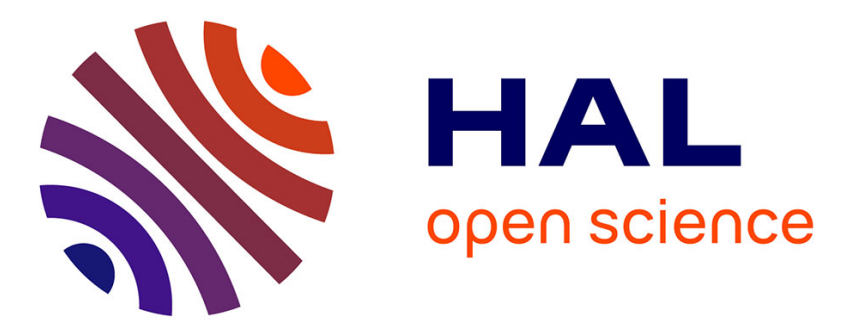

\title{
Preliminary ex vivo 3D microscopy of coronary arteries using a standard 1.5 T MRI scanner and a superconducting RF coil
}

\author{
M. Poirier-Quinot, J.-C. Ginefri, F. Ledru, P. Fornes, L. Darrasse
}

\section{- To cite this version:}

M. Poirier-Quinot, J.-C. Ginefri, F. Ledru, P. Fornes, L. Darrasse. Preliminary ex vivo 3D microscopy of coronary arteries using a standard 1.5 T MRI scanner and a superconducting RF coil. Magnetic Resonance Materials in Physics, Biology and Medicine, 2005, 18 (2), pp.89-95. 10.1007/s10334-0040097-x . hal-02269946

\section{HAL Id: hal-02269946 \\ https://hal.science/hal-02269946}

Submitted on 23 Aug 2019

HAL is a multi-disciplinary open access archive for the deposit and dissemination of scientific research documents, whether they are published or not. The documents may come from teaching and research institutions in France or abroad, or from public or private research centers.
L'archive ouverte pluridisciplinaire HAL, est destinée au dépôt et à la diffusion de documents scientifiques de niveau recherche, publiés ou non, émanant des établissements d'enseignement et de recherche français ou étrangers, des laboratoires publics ou privés. 
archives-ouvertes

\section{Preliminary ex vivo 3D microscopy of coronary arteries using a standard 1.5 T MRI scanner and a superconducting RF coil}

P. Fornes, Marie Poirier-Quinot, J.-C. Ginefri, L. Darrasse, F. Ledru, M. Poirier-Quinot

\section{To cite this version:}

P. Fornes, Marie Poirier-Quinot, J.-C. Ginefri, L. Darrasse, F. Ledru, et al.. Preliminary ex vivo 3D microscopy of coronary arteries using a standard 1.5 T MRI scanner and a superconducting RF coil. Magnetic Resonance Materials in Physics, Biology and Medicine, Springer Verlag, 2005, 18 (2), pp.89-95. 10.1007/s10334-004-0097-x . hal-02269946

\section{HAL Id: hal-02269946 \\ https://hal.archives-ouvertes.fr/hal-02269946}

Submitted on 23 Aug 2019

HAL is a multi-disciplinary open access archive for the deposit and dissemination of scientific research documents, whether they are published or not. The documents may come from teaching and research institutions in France or abroad, or from public or private research centers.
L'archive ouverte pluridisciplinaire HAL, est destinée au dépôt et à la diffusion de documents scientifiques de niveau recherche, publiés ou non, émanant des établissements d'enseignement et de recherche français ou étrangers, des laboratoires publics ou privés. 


\section{P.-Quinot \\ J.-C. Ginefri \\ F. Ledru \\ P. Fornes \\ L. Darrasse}

\section{Preliminary ex vivo 3D microscopy of coronary arteries using a standard 1.5-T MRI scanner and a superconducting RF coil}

Received: 7 May 2004

Revised: 1 December 2004

Accepted: 1 December 2004

Published online:
M. P.-Quinot (文) · J.-C. Ginefri

L. Darrasse

U2R2M, bat220, Université Paris-Sud,

91405 Orsay, France

E-mail : marie.pquinot@u2r2m.u-psud.fr

Tel.: +33-1-69154134

Fax: +33-1-69154136

F. Ledru

Cardiology Department, Hôpital Européen

Georges Pompidou, 75015 Paris, France

P. Fornes

Pathology Department, Hôpital Européen

Georges Pompidou, 75015 Paris, France

\author{
Abstract This paper presents the \\ feasibility of three-dimensional (3D) \\ magnetic resonance (MR) histology \\ of atheromatous coronary lesions in \\ the entire human heart ex vivo using \\ a standard 1.5-T scanner and a \\ 12-mm high-temperature \\ superconducting (HTS) surface coil. \\ The HTS coil was a five-turn \\ transmission-line resonator operated \\ at $77 \mathrm{~K}$, affording a signal-to-noise \\ ratio (SNR) gain of about ninefold \\ as compared to a similar, \\ room-temperature copper coil. Local \\ microscopy at the surface of an \\ explanted, entire heart was achieved \\ by a $3 \mathrm{D}$ spoiled gradient echo \\ sequence and assessed by \\ comparison with conventional \\ histology. One hundred and twenty \\ four adjacent cross sections of the \\ coronary artery, with voxels of \\ $59 \times 59 \times 100 \mu \mathrm{m}^{3}$ and an SNR of
}

about 20, were obtained in $25 \mathrm{~min}$. Consecutive data sets were combined to reconstruct extended views along the artery. Compared to histology, MR microscopy allowed precise nondestructive 3D depiction of the architecture of the atheromatous plaques. This is the first report of microscopic details (less than $10^{-3} \mathrm{~mm}^{3}$ voxels) of diseased arteries obtained in an entire human heart preserving the arterial integrity and the spatial geometry of atheroma. This noninvasive microscopy approach using a HTS surface coil might be applied in vivo to study the architecture and components of superficial human structures, using routine MR scanners.

Keywords MRI - Microscopy · Superconducting RF coil - Coronary artery disease

\section{Introduction}

The most recent histological studies in atherosclerosis have shown that the fate of atheromatous lesions is crucially determined by the structure, composition and geometry of the plaque [1-4]. In particular, thinning and inflammation of the fibrous cap, spatial extent of the underlying lipid core, abruptness of inlet and outlet stenosis angles, and extent of the compensatory remodelling have been identified as characteristics of potentially vulnerable and thrombosis-prone atheromatous plaques. These critical features, especially the thinning and inflammatory foci of the fibrous cap, have dimensions of $50 \mu \mathrm{m}$ or less and are hardly accessible by current MRI techniques.
Ex vivo high-spatial-resolution imaging of excised carotid or coronary arteries by magnetic resonance (MR) microscopy at fields up to $9.4 \mathrm{~T}$ has been successfully applied to identify the high-risk structures nondestructively [5-9]. However, dedicated high-field microscopes are currently available only with reduced bore size and do not allow for the study of entire organs such as the human heart. To investigate initiation and development of human atherosclerosis, preserving the integrity of the coronary artery and its donor organ, is important in order to assess geometric variables such as plaque conformation both in the vessel wall and in the vessel lumen, besides plaque composition and structure.

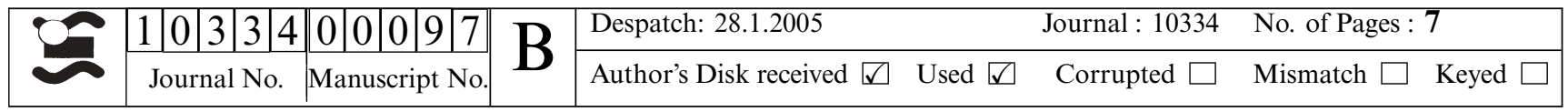


On the other hand, standard clinical scanners are available with bores allowing the study of large explanted entire organs. In vivo imaging of carotid and coronary arteries even allows the differentiation between the vessel lumen and some components of the vessel wall such as mural thrombus, fibrous components and lipidic core [10-17]. So far, however, the spatial resolution obtained in 1.5-T body scanners has remained too low to obtain detailed microstructural information of prognostic importance for the plaque outcome. The insufficient spatial resolution is due to an intrinsic signal-to-noise ratio (SNR) limitation with conventional radio frequency $(\mathrm{RF})$ coils at $1.5 \mathrm{~T}$, while current gradient systems would have sufficient spatial encoding power to achieve voxel dimensions below $100 \mu \mathrm{m}$. A possible approach is to call for intravascular coils [18-23], which allow access to inner vessels with spatial resolution of the order of $10^{-2} \mathrm{~mm}^{3}$. Alternatively, the work presented here is focused on the possibility of obtaining microscopic resolution in superficial structures accessed from the outer surface.

Small cryogenic RF coils at $77 \mathrm{~K}$, made of either copper or high-temperature superconducting (HTS) material, have been shown to increase significantly the SNR and the spatial resolution at low field strength over large anatomical areas [24,25], and in high-field MR microscopes with small-sized samples [26,27]. When large samples are involved, reducing the size of surface coils achieves large SNR benefits due to both a higher signal coming from a stronger magnetic coupling with the sample and a lower noise coming from a smaller volume of tissue viewed by the coil. Cryogenic operation is needed when the intrinsic coil noise becomes comparable to or greater than the tissueinduced noise and limits the SNR improvement provided by the size reduction, a situation encountered on current 1.5-T scanners at a typical coil size of $1 \mathrm{~cm}[28,29]$.

In this preliminary work, we explore the feasibility of studying the three-dimensional (3D) morphology of atheromatous coronary lesions in the entire explanted human heart using a commercially available 1.5-T scanner and a 12-mm HTS surface coil. The value of the microstructural information given by the MR images is assessed by reference to conventional histology.

\section{Materials and methods}

\section{HTS coil}

The HTS surface coil was a five-turn transmission-line resonator with an outer diameter of $14.6 \mathrm{~mm}$, operated at $77 \mathrm{~K}$, which has been fully described elsewhere [30]. The unloaded quality factor (Q) in a 1.5-T magnetic field was about 11,000 . It decreased to 5900 when loaded by an excised human heart.

The SNR gain provided by the HTS coil, as compared to a room-temperature copper coil having exactly the same geometry and an unloaded Q factor of about 110 [31], was estimated using electrical measurements of loaded and unloaded quality factors, $Q_{l}$ and $Q_{u}$, and taking into account the noise contribution from the standard preamplifier of the MRI system. Replacing the heart by a phantom made of a $500-\mathrm{ml}$ perfusion bag, filled with saline water of $38.5 \mathrm{mmol} / 1$, the loaded Q measurements achieved values of about 2850 and 106 for the HTS and copper coils, respectively.

In addition the actual SNR gain was directly measured on MR images acquired with the saline phantom using the same conditions and same imaging protocol for both coils. A 2D spin echo sequence was applied with a repetition time (TR)/echo time (TE) of $500 / 35 \mathrm{~ms}$, matrix of $512 \times 512$, field of view (FOV) of $20 \times 20 \mathrm{~mm}^{3}$, total acquisition bandwidth of $\pm 3.91 \mathrm{kHz}$ and axial slice thickness of $900 \mu \mathrm{m}$. The SNR value was extracted using the average signal intensity over a region of $10 \times 10$ pixels located on the coil axis, close to the surface of the phantom, and the standard deviation over a region of $40 \times 200$ pixels drawn in the background outside of the sample. The SNR gain measured from the images was about $5.2 \pm 0.1$.

An effective noise temperature of the coil, $T_{\text {eff }}$, can be defined from the respective noise contributions of the coil and the sample, according to their respective temperatures, $T_{c}$ and $T_{s}$ [32]. Assuming that the coil inductance does not vary significantly upon loading, $T_{\text {eff }}$ is given by:

$T_{\text {eff }}=\frac{T_{s}\left(Q_{u}-Q_{l}\right)+T_{c} Q_{l}}{Q_{u}}$

Using the equivalent noise temperature of the preamplifier, $T_{N}$, the SNR can then be written as [33]:

$\mathrm{SNR} \propto \sqrt{\frac{Q_{l}}{T_{N}+T_{\text {eff }}}}$

According to the manufacturer's specifications, the noise factor of the preamplifier is less than $1 \mathrm{~dB}$, corresponding to a $T_{N}$ value below $75 \mathrm{~K}$. The SNR gain provided by the HTS coil on the saline phantom, as evaluated from Eqs. 1 and 2, is found to be $5.5 \pm 0.2$. The same calculation applied to the loading by the excised heart gives an estimated gain of about 9 .

\section{Heart preparation}

An entire human heart was collected soon after death and kept in formaldehyde. It was obtained from an elder subject (older than 75 years) who had decided to give his body to our School of Medicine for research and teaching purposes after his death. During preparation of the heart, the coronary arteries were flushed with saline to remove blood and cellular debris. The heart was fixed into a plastic holder so that the coronary artery to be analyzed (left anterior descending (LAD) or circumflex (CX) artery) was longitudinally oriented along the axis of the magnetic field. The plastic holder was then positioned in the MR scanner so that the arterial segment of interest was placed against the HTS coil. A graduated translation mechanism allowed sequential imaging of the entire artery using stepwise translations along its longitudinal axis (see Fig. 1). 


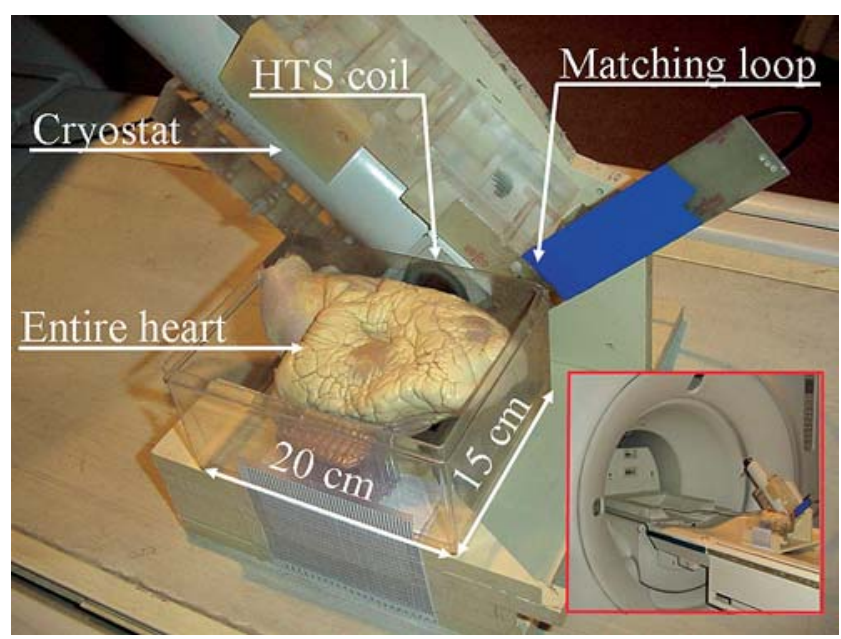

Fig. 1 Photograph showing the entire heart fixed into a plastic holder, with the graduated translation mechanism, in imaging setup. The inset is an overall view of the whole system in the MR scanner

Imaging sequence

Magnetic resonance imaging (MRI) was performed at CIERM (Bicêtre Hospital, France), a clinical facility equipped with a standard 1.5-T MR scanner (Signa, GE medical system, Milwaukee, WI, USA). The scanner delivers a maximum gradient amplitude of $22 \mathrm{mT} / \mathrm{m}$ with a rise time of $288 \mu \mathrm{s}$. The HTS surface coil was operated in transmit/receive mode using the standard scanner electronics. 3D data sets were acquired using the standard RF spoiled gradient echo sequence, FOV of $30 \times 15 \times$ $12.4 \mathrm{~mm}^{3}$, matrix of $512 \times 256 \times 124$, TR/TE of $46.4 / 13.3 \mathrm{~ms}$, and total acquisition bandwidth $\pm 7.81 \mathrm{kHz}$. The total scanning time was $24.55 \mathrm{~min}$ using a single excitation. The excitation level was adjusted empirically in order to reach the maximal SNR in the image at the coronary level.

\section{Histology}

Following the MR study, the whole coronary artery of interest was excised from the heart and cut into 5-mm-thick cross sections. All sections were individually embedded in paraffin. Then, $3-\mu \mathrm{m}$-thick sections were obtained from each paraffin block with a microtome and stained with hematoxylin-eosin (HE). Finally, five histologic sections were selected for the correlation study using side branches, such as septal, diagonal or marginal branches, as localization markers allowing correct matching with the MR images.

\section{Results}

\section{Imaging}

Figure $2 \mathrm{~b}, \mathrm{c}$, and d show cross-sectional slices at different levels of the coronary artery obtained by the 3D

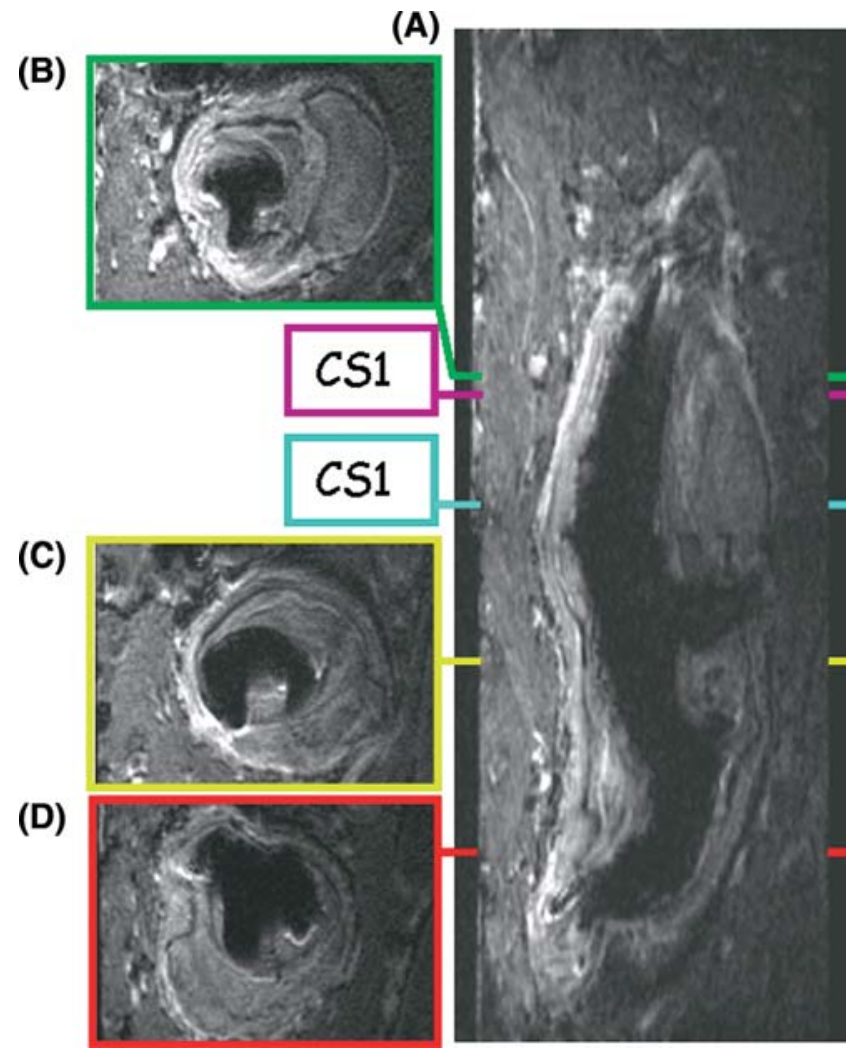

Fig. 2 Three-dimensional imaging of an excised, but not dissected, coronary artery. $\mathbf{a} 8.43 \times 22.38 \mathrm{~mm}^{2}$ sagittal view reconstructed along the artery axis from two data sets, each containing 124 axial slices of $100-\mu \mathrm{m}$ thickness with in-plane resolution of $59 \times 59 \mu \mathrm{m}^{2} .15 \times$ $10.6 \mathrm{~mm}^{2}$ axial cross sections (b), (c) and (d) sampled at different levels of the coronary artery. The scanning time for each data set was $24.55 \mathrm{~min}$. CS1 and CS2 indicate the localization of the axial cross sections compared with histological slices and displayed on Fig. 4b and Fig. $5 \mathrm{~b}$ respectively

acquisition sequence with $59 \times 59 \mu \mathrm{m}^{2}$ in-plane resolution and $100-\mu \mathrm{m}$ slice thickness. Figure $2 \mathrm{a}$ shows a view reconstructed along the arterial axis after combining two overlapping data sets, each containing 124 slices. Figure 3 indicates the SNR values averaged over a series of $20 \mathrm{im}$ ages extracted at the centre of each $3 \mathrm{D}$ sets. The SNR on each image was defined as the mean signal intensity over 25 pixels divided by the standard deviation of the background noise over 5400 pixels.

\section{Histology}

With reference to histology, all plaque components were clearly delineated by MR microscopy, as illustrated on the two different cross sections displayed in Figs. 4 and 5. In Fig. 4, the atherosclerotic plaque is composed of a lipidic core and a thick fibrous cap that is partially calcified. The external border of the plaque is bulging outwards. This feature is known as a compensatory remodelling of 


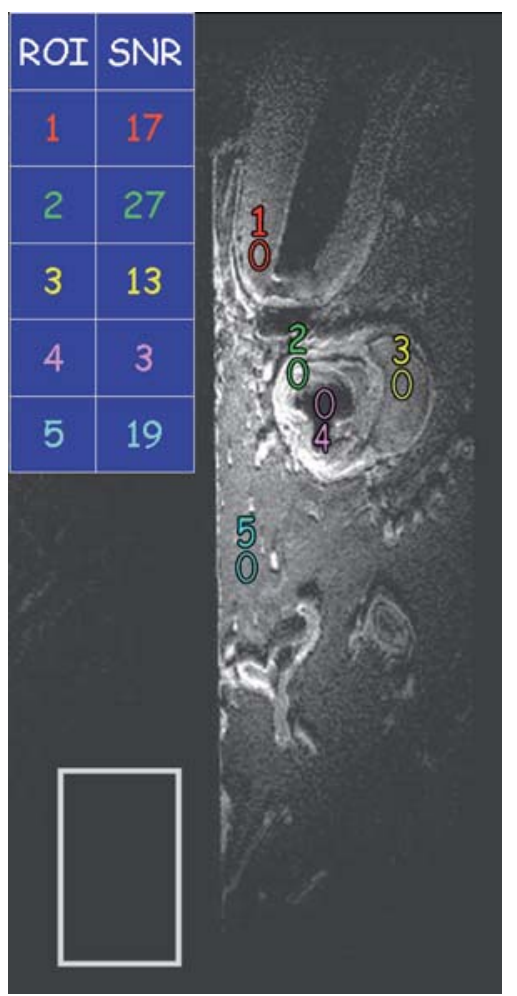

Fig. 3 Signal-to-noise ratio values averaged over 20 adjacent cross sections extracted at the center of each 3D data set. The signal intensity was measured in the wall of the left appendage of the heart (1), in a fibrous area of the artery wall (2), in a large calcified area (3), in the water-filled lumen of the artery (4) and in the myocardium (5). The noise reference was taken over the rectangular area at the bottom left of the image

the vessel wall, accommodating the plaque that developed consequently while minimally compromising the arterial lumen. There was no thrombosis nor intra-plaque haemorrhage. The fibrous cap was not ruptured nor ulcerated. In Fig. 5, the plaque is mainly composed of dense fibrous tissue with no lipidic core but massive circumferential calcifications. There was neither thrombosis, intra-plaque haemorrhage nor any ruptured or ulcerated fibrous cap. In both sections, the plaque features are currently considered as those of stable atherosclerotic plaques.

\section{Discussion}

This preliminary work demonstrates the feasibility of nondestructive 3D MR microscopy of atheromatous lesions in the entire human heart using a standard 1.5-T body scanner and a 12-mm HTS surface coil. This is the first time that high-quality MR images have been acquired with voxels smaller than $10^{-3} \mathrm{~mm}^{3}$ in a human organ larger than a few centimeters. The voxel dimensions of $59 \times 59 \times$
$100 \mu \mathrm{m}^{3}$ give access to most of the critical microstructural information needed to fully characterize the atheromatous plaque and its thrombosis-prone potential. Besides, the extended 3D coverage allows the study of the artery and plaque in its longitudinal axis. Such information is barely obtained by other imaging techniques, conventional histology itself being an inherently destructive and slow procedure. In the vista of improving our knowledge in the field of human atherosclerosis, 3D MR histology of entire ex vivo hearts may prove to be useful to better analyze the complex interaction between plaque composition and architecture, lumen and arterial deformation and eventually mechanical resistance of the fibrous cap to shear stress.

To better characterize the plaque and to identify highrisk coronary artery lesions based on the specificity of the lipid core, further analysis with multiple contrast sequences combining $T_{1}, T_{2}$ and proton density weighting would be needed [34-36,6,12]. However this preliminary work was done using the HTS coil in transmit/receive mode, only allowing for weak and somewhat inaccurate $\mathrm{T}_{1}$-weighted image contrast. Further investigations will require operating the coil in receive-only mode, uniform excitation being achieved by a larger transmit coil. The later would also help to extend the actual FOV available from the HTS coil, which is in part limited due to the nonuniform transmission achieved by the HTS coil.

The 12-mm HTS surface coil provided the needed sensitivity for detailed imaging of the coronary arteries at a SNR of about 20 within half an hour at $1.5 \mathrm{~T}$, with an estimated SNR advantage of about nine compared to the equivalent room-temperature copper coil. According to the unloaded/loaded $Q$ values of about $11,000 / 5900$ and respective sample and coil temperatures of $300 \mathrm{~K}$ and $80 \mathrm{~K}$, the noise power induced from the excised heart dominates the noise power of the HTS coil by a factor of 3.2. The noise power from the room-temperature copper coil, corresponding to an unloaded $Q$ a hundred times lower than with the HTS coil, thus dominates the noise power from the excised heart by a factor of 120 . From the theory with conventional coils [37], the SNR provided at the RF coil output is linearly dependent on the field strength in a regime dominated by the sample noise, while the dependence is faster, to the power 7/4, when the coil noise dominates. Extrapolation of the copper coil behavior with this law gives the minimal field strength, of about $5 \mathrm{~T}$, providing the same SNR performance as the HTS coil at $1.5 \mathrm{~T}$. Moreover, larger acquisition bandwidths are generally involved at higher magnetic fields, in order to account for the larger frequency dispersion arising from chemical shifts and internal susceptibility differences. This leads to a final SNR in MR images which is much less rapidly increasing with field strength than simply expected as above from the noise source behavior. Finally, the longitudinal-relaxation enhancement by macromolecules tends 
Fig. 4 a Conventional histology from a cross section of $3-\mu \mathrm{m}$ thickness of the left anterior descending artery stained with $\mathrm{HE}$ and displayed at $40 \times$ magnification. b The corresponding MRI cross section (CS1), localized as indicated in Fig. 2

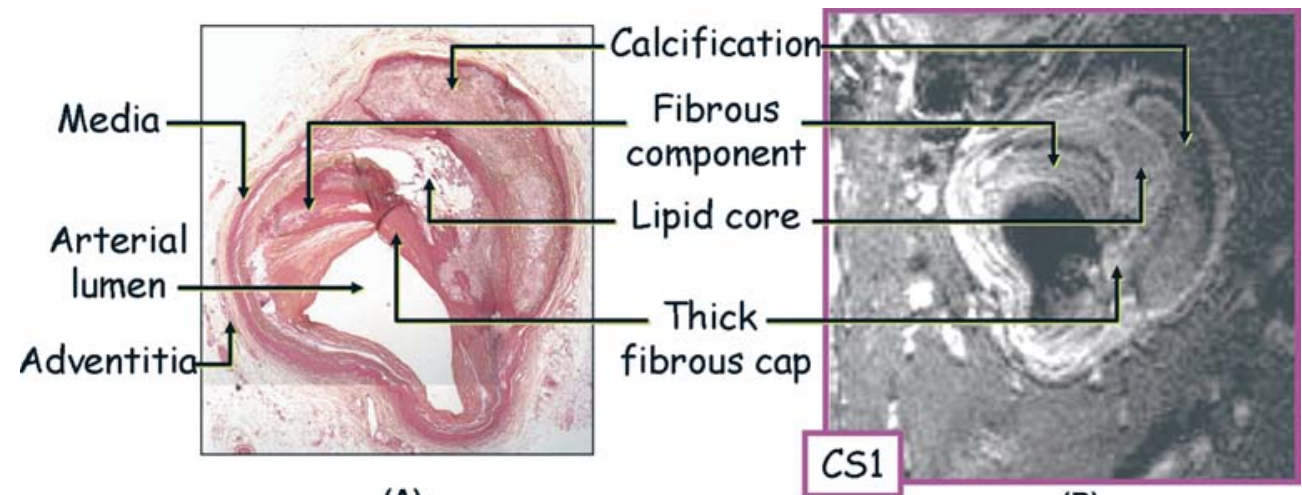

(A)

(B)
Fig. 5 a Conventional histology from a cross section of $3-\mu \mathrm{m}$ thickness of the left anterior descending artery stained with HE and displayed at $40 \times$ magnification. b The corresponding MRI cross section (CS2), localized as indicated in Fig. 2

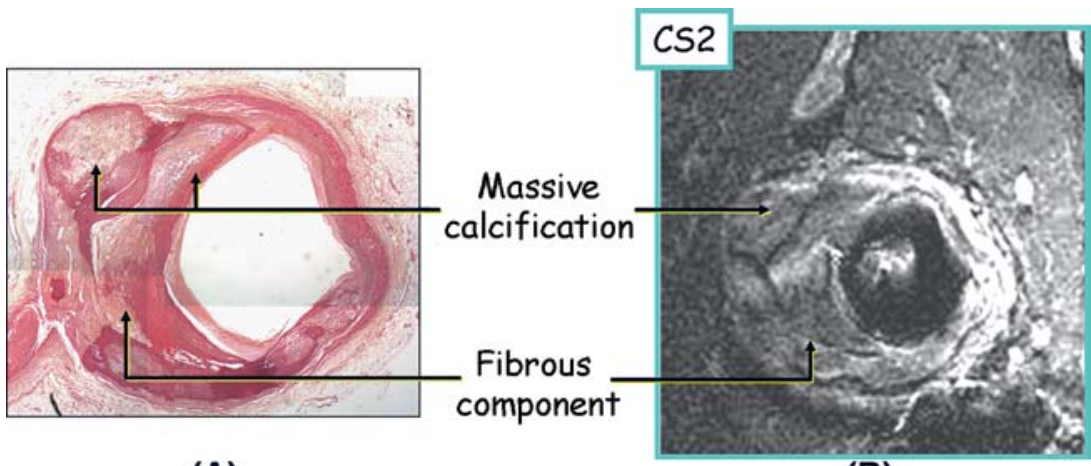

(A)
(B) to vanish at high fields, leading to reduced $\mathrm{T}_{1}$-contrast potentiality [38]. The ability to retain the contrast mechanisms pertinent to the field strength of $1.5 \mathrm{~T}$, involved in most clinical applications, is an additional argument in favor of the proposed HTS coil approach to increase the SNR and achieve local microscopy.

The present work has been focused on the examination of inert organs, i.e. in a context that facilitates preliminary studies with regard to technical difficulties inherent to HTS coils. As for the future of in vivo investigations of arterial diseases, there is a growing development of in vivo models, involving small animals such as mice, aimed at better understanding the initiation, development and complications of atherosclerosis and to evaluate new therapies [39]. In such approaches using MRI, high-field microscopes yield FOVs comparable to that obtained in the present work. A recent work in the mouse [40] suggested that HTS surface coils at $1.5 \mathrm{~T}$ would be an interesting alternative to dedicated high-field MR microscopes for studying vascular diseases in small-animal models. Regarding in vivo studies of human vascular diseases $[41,42]$, the use of small superconducting surface coils to improve the sensitivity will be inherently limited by the lack of penetration inside the body, restricting investigations to superficial subcutaneous vessels such as carotid, temporal or digital arteries. On the other hand intravas- cular MRI has been successfully applied to solve the penetration problem, but with voxels currently limited to about $98 \times 98 \times 3000 \mu^{3}$ [18], i.e. more than one order of magnitude worse than the resolution accessed here. Moreover, besides being invasive, intravascular imaging has not been fully validated for human application regarding power deposition and related thermal effects. Thus we believe that the HTS technology, being complementary to the intravascular approach that is more suited for accessing to deep structures, could be helpful to study atherosclerosis at the level of superficial vessels in humans.

Acknowledgements This work has been supported by a grant from the French Ministry of Research. 


\section{References}

1. Davies MJ, Woolf N, Rowles P,Richardson PD (1994) Lipid and cellular constituents of unstable human aortic plaques. Basic Res Cardiol 1:33-39

2. Falk E, Shah PK, Fuster V (1995) Coronary plaque disruption. Circulation 92:657-671

3. Ledru F, Théroux T, Lespérance J, Laurier J, Ducimetière $P$, Guermonprez J, Diébold B, Blanchard D (1999) Geometric features of coronary artery lesions favoring acute occlusion and myocardial infarction: a quantitative angiographic study. J Am Coll Cardiol 33:1353-1361

4. Schoenhagen P, McErlean ES, Nissen SE (2000) The vulnerable coronary plaque. J Cardiovasc Nurs 15:1-12

5. Serfaty JM, Chaabane L, Tabib A, Chevallier JM, Briguet A, Douek PC (2001) Atherosclerotic plaques: classification and characterization with T2-weighted high-spatial-resolution MR imaging - an in vitro study. Radiology 219:403-410

6. Shinnar M, Fallon JT, Wehrli S, Levin M, Dalmacy D, Fayad ZA, Badimon JJ, Harrington M, Harrington E, Fuster V (1999) The diagnostic accuracy of ex vivo MRI for human atherosclerotic plaque characterization. Arterioscler Thromb Vasc Biol 19:2756-2761

7. Toussaint JF, Southern JF, Fuster V, Kantor HL (1995) T2-weighted contrast for NMR characterization of human atherosclerosis. Arterioscler Thromb Vasc Biol 15:1533-1542

8. Winn WB, Schmiedl UP, Reichenbach DD, Beach KW, Nghiem H, Dimas C, Daniel E, Maravilla KR, Yuan C (1998) Detection and characterization of atherosclerotic fibrous caps with T2-weighted MR. AJNR Am J Neuroradiol 19:129-134

9. Yuan C, Mitsumori LM, Beach KW, Maravilla KR (2001) Carotid atherosclerotic plaque: noninvasive MR characterization and identification of vulnerable lesions. Radiology 221:285-299

10. Botnar RM, Stuber M, Kissinger KV, Kim WY, Spuentrup E, Manning WJ (2000) Noninvasive coronary vessel wall and plaque imaging with magnetic resonance imaging. Circulation 102:2582-2587

11. Hatsukami TS, Ross R, Polissar NL, Yuan C (2000) Visualization of fibrous cap thickness and rupture in human atherosclerotic carotid plaque in vivo with high-resolution magnetic resonance imaging. Circulation 102:959-964
12. Toussaint JF, LaMuraglia GM, Southern JF, Fuster V, Kantor HL (1996) Magnetic resonance images lipid, fibrous, calcified, hemorrhagic, and thrombotic components of human atherosclerosis in vivo. Circulation 94:932-938

13. von Ingersleben G, Schmiedl UP, Hatsukami TS, Nelson JA, Subramaniam DS, Ferguson MS, Yuan C (1997) Characterization of atherosclerotic plaques at the carotid bifurcation: correlation of high-resolution MR imaging with histologic analysis - preliminary study. Radiographics 17:1417-1423

14. Yuan C, Beach KW, Smith LH, Jr., Hatsukami TS (1998) Measurement of atherosclerotic carotid plaque size in vivo using high resolution magnetic resonance imaging. Circulation 98:2666-2671

15. Yuan C, Kerwin WS, Ferguson MS, Polissar N, Zhang S, Cai J, Hatsukami TS (2002) Contrast-enhanced high resolution MRI for atherosclerotic carotid artery tissue characterization. J Magn Reson Imaging 15:62-67

16. Yuan C, Mitsumori LM, Ferguson MS, Polissar NL, Echelard D, Ortiz G, Small R, Davies JW, Kerwin WS, Hatsukami TS (2001) In vivo accuracy of multispectral magnetic resonance imaging for identifying lipid-rich necrotic cores and intraplaque hemorrhage in advanced human carotid plaques. Circulation 104:2051-2056

17. Yuan C, Zhang Sx SX, Polissar NL, Echelard D, Ortiz G, Davis JW, Ellington E, Ferguson MS, Hatsukami TS (2002) Identification of fibrous cap rupture with magnetic resonance imaging is highly associated with recent transient ischemic attack or stroke. Circulation 105:181-185

18. Atalar E, Bottomley PA, Ocali O, Correia LC, Kelemen MD, Lima JA, Zerhouni EA (1996) High resolution intravascular MRI and MRS by using a catheter receiver coil. Magn Reson Med 36:596-605

19. Qiu B, Yeung CJ, Du X, Atalar E, Yang X (2002) Development of an intravascular heating source using an MR imaging guidewire. J Magn Reson Imaging 16:716-720

20. Sirol M IV, Mani V, Aguinaldo JGS, Fallon JT, Misselwitz B, Weinmann HJ, Fuster V, Toussaint JF, Fayad ZA (2004) Lipid-rich atherosclerotic plaques detected by gadofluorine-enhanced in vivo magnetic resonance imaging. Circulation 109:2890-2896
21. Susil RC, Yeung CJ, Atalar E (2003) Intravascular extended sensitivity (IVES) MRI antennas. Magn Reson Med 50:383-390

22. Worthley SG, Helft G, Fuster V, Fayad ZA, Shinnar M, Minkoff LA, Schechter C, Fallon JT, Badimon JJ (2003) A novel nonobstructive intravascular MRI coil: in vivo imaging of experimental atherosclerosis. Arterioscler Thromb Vasc Biol 23:346-350

23. Yang X, Atalar E (2000) Intravascular MR imaging-guided balloon angioplasty with an MR imaging guide wire: feasibility study in rabbits. Radiology 217:501-506

24. Hall AS, Alford N, Button TW, Gilderdale DJ, Gehring KA, Young IR (1991) Use of high temperature superconductor in a receiver coil for magnetic resonance imaging. Magn Reson Med 20:340-343

25. van Heteren JG, James TW, Bourne LC (1994) Thin film high temperature superconducting RF coils for low field MRI. Magn Reson Med 32:396-400

26. Black RD, Early TA, Roemer PB, Mueller OM, Mogro-Campero A, Turner LG, Johnson GA (1993) A high-temperature superconducting receiver for nuclear magnetic resonance microscopy. Science 259:793-795

27. Styles P, Soffe NF, Scott CA, Cragg DA, Row F, White DJ, White PCJ (1984) A high-resolution NMR probe in which the coil and preamplifier are cooled with liquid helium. J Magn Reson 60:397-404

28. Ginefri JC, Darrasse L, Crozat P (2001) Superconducting surface coil for in vivo MRI microscopy of the skin at 1.5 teslas. ITBM-RBM 22:107-115

29. Wright AC, Hee Kwon S, Wehrli FW (2000) In vivo MR micro imaging with conventional radiofrequency coils cooled to 77 degrees K. Magn Reson Med 43:163-169

30. Ginefri JC, Darrasse L, Crozat P (2001) High-temperature superconducting surface coil for in vivo microimaging of the human skin. Magn Reson Med 45:376-382

31. Coutrot AL, Dufour-Gergam E, Quemper JM, Martincic E, Gilles JP, Grandchamp JP, Matlosz M, Sanchez A, Darasse L, Ginefri JC (2002) Copper micromoulding process for NMR microinductors realization. Sens Actuators a-Phys 99:49-54

32. Jerosch-Herold M, Kirschman R (1989) Potential benefits of a cryogenically cooled NMR probe for room-temperature samples. J Magn Reson 85:141-146 
33. Odoj F, Rommel E, v Kienlin M, Haase A (1998) A superconducting probehead applicable for nuclear magnetic resonance microscopy at $7 \mathrm{~T}$. Rev Sci Instrum 69:2708-2712

34. Gold GE, Pauly JM, Glover GH, Moretto JC, Macovski A, Herfkens RJ (1993) Characterization of atherosclerosis with a $1.5-\mathrm{T}$ imaging system. J Magn Reson Imaging 3:399-407

35. Martin AJGA, Henkelman RM (1995) High-resolution MR imaging of human arteries. J Magn Reson Imaging 5:93-100

36. Pan XMSD, Reilly LM, Bowersox JC, Murray SP, Anderson CM, Gooding GAW, Rapp JH (1995) Assessment of carotid artery stenosis by ultrasonography, conventional angiography, and magnetic resonance angiography: correlation with ex vivo measurement of plaque stenosis. J Vasc Surg 21:82-89
37. Hoult DLP (1979) The sensitivity of the zeugmatographic experiment involving human samples. J Magn Reson 34:425-433

38. Mansfield P, Morris PG (1982) NMR imaging in biomedicine. Suppl 2 Adv Magn Reson

39. Chaabane L, Canet E, Serfaty JM, Contard F, Guerrier D, Douek P, Briguet A (2000) Microimaging of atherosclerotic plaque in animal models. Magma 11:58-60

40. Poirier-Quinot MG, J-C Robert, Darrasse L (2004) Feasibility of in vivo microimaging of the mouse in a conventional $1.5 \mathrm{~T}$ body scanner equipped with a $12 \mathrm{~mm}$ HTS surface coil. In: 12th Annual ISMRM Meeting, Kyoto, 1754
41. Fayad ZA, Fuster V, Fallon JT, Jayasundera T, Worthley SG, Helft G, Aguinaldo JG, Badimon JJ, Sharma SK (2000) Noninvasive in vivo human coronary artery lumen and wall imaging using black-blood magnetic resonance imaging. Circulation 102:506-510

42. Yuan C, Lin E, Millard J, Hwang JN (1999) Closed contour edge detection of blood vessel lumen and outer wall boundaries in black-blood MR images. Magn Reson Imaging 17:257-266 